\title{
Preparation and Characterization of the $\beta$-Cyclodextrin Inclusion Complex with Benzbromarone
}

\author{
Iran L. Sousa, ${ }^{a, b}$ Caio M. Porto, ${ }^{\oplus a}$ Kátia C. Bassani, ${ }^{a}$ Milene H. Martins, ${ }^{a}$ \\ Francisco B. T. Pessine ${ }^{a}$ and Nelson H. Morgon ${ }^{\circledR}, a$ \\ anstituto de Química, Universidade Estadual de Campinas, 13083-861 Campinas-SP, Brazil \\ ${ }^{b}$ Instituto Federal de Educação, Ciência e Tecnologia do Sertão Pernambucano, \\ 56200-000 Ouricuri-PE, Brazil
}

\begin{abstract}
Benzbromarone (BZB) is a drug that has diuretic activity and is used in the gout treatment. Its therapeutic efficiency is decreased by its low water solubility $\left(11.8 \mathrm{mg} \mathrm{L}^{-1}\right)$ and highly hydrophobic aspect $(\log \mathrm{P} 2.7)$, which are responsible for affecting its intestinal absorption and bioavailability. BZB inclusion complex (IC) aims at increasing the drug solubility in water and reduce adverse effects resulting in more efficient formulations. The coprecipitation encapsulating method was used to obtain the IC of BZB in $\beta$-cyclodextrin $(\beta-C D)$ and the complex (BZB@ $\beta$-CD) was characterized via physical-chemical analysis. A comparative study of time-dependent density functional theory (TD-DFT) and configuration interaction singles (CIS), along with "our own $\mathrm{N}$-layered integrated molecular orbital and molecular mechanics" (ONIOM) method, has been carried out on the UV-Vis absorption of BZB and BZB@ $\beta-C D$. The qualitative description of the simulated spectrum, given by ONIOM(CIS:PM6), is in accord with the formation of BZB @ $\beta-\mathrm{CD}$. It only became possible when phosphate buffer $(\mathrm{pH} 7.4)$ was used to prepare the solutions, since the complex formation did not occur in deionized water or buffered acid. Furthermore, by using the Job plot, the Scatchard method and fluorescence, it was possible to conclude that the complex molecular stoichiometry was $1: 1$ (1 BZB to $1 \beta$-CD).
\end{abstract}

Keywords: benzbromarone, inclusion complex, $\beta$-cyclodextrin, fluorescence, ONIOM(TD-DFT:PM6), ONIOM(CIS:PM6)

\section{Introduction}

Benzbromarone (BZB) is chemically called 3,5-dibromo-4-hydroxyphenyl-2-ethyl-3-benzofuranyl methanone. It is a solid with melting point of around $161-163{ }^{\circ} \mathrm{C}$, molecular weight $424.083 \mathrm{~g} \mathrm{~mol}^{-1}$, essentially insoluble in water $\left(11.8 \mathrm{mg} \mathrm{L}^{-1}\right.$ at $\left.25^{\circ} \mathrm{C}, \log \mathrm{P} 2.7\right)$, slightly soluble in ethanol, soluble in acetone and methylene chloride and freely soluble in chloroform. ${ }^{1}$ Its molecular formula is $\mathrm{C}_{17} \mathrm{H}_{12} \mathrm{Br}_{2} \mathrm{O}_{3}$ and its chemical structure is shown in Figure 1. It was introduced in clinical therapy in 1970 for the treatment of gout. ${ }^{2}$ Initially, it was associated with few adverse effects and so it was approved in approximately 20 countries in Europe, Asia and South America. However, in 2003, the manufacturer Sanofi-Synthelabo issued a recall of this drug from the market after several serious hepatic effects being reported. However, it is still marketed in many countries by other companies. ${ }^{3}$ This drug blocks the

*e-mail: nhmorgon@unicamp.br tubular reabsorption of uric acid, making it available for the treatment of hyperuricemy in patients with gout.

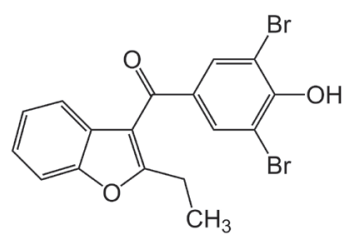

Figure 1. Chemical structure of neutral BZB.

The study of drugs complexation in encapsulating active pharmaceutical ingredients (API), that increase the drug's solubility ${ }^{4,5}$ and minimize its adverse effects, has shown to be a promising alternative to achieve more effective and less toxic therapeutic formulations.

Cyclodextrins (CDs) are cyclic polysaccharides of glucopyranose units linked by $\alpha-1,4$ bonds, resulting in a molecular structure with a toroidal geometry. At $25^{\circ} \mathrm{C}$, $\mathrm{CDs}$ are crystalline, homogeneous and hygroscopic substances. Typical CDs are composed of 6,7 and 
8 glucopyranose units, being called $\alpha, \beta$ and $\gamma$-CDs, respectively. Furthermore, they have a spatial conformation in which different chemical polarities are found in the same molecule. For example, the interior cavity is predominantly hydrophobic while the outer part of the molecule is hydrophilic ${ }^{6}$ and responsible for its aqueous solubility. The molecule polarity difference between the interior and the exterior of the cavity allows the use of CDs as encapsulating agents for hydrophobic molecules, once these are retained in the cavity by van der Waals forces. ${ }^{7,8}$

The main reasons for the use of CDs in the industry are: ${ }^{9} \mathrm{CD}$ production is enzymatically done using starch, a renewable source; the production of CDs does not pollute the environment; increase in production helps to decrease costs by expanding the demand for many industries and applications, such as food, pharmaceutical, cosmetic, etc.; $\mathrm{CD}$ inclusion compounds alter many chemical and physical properties, such as solubility, chemical stability, spectroscopic properties, etc.; toxicity can be reduced by using appropriate $\mathrm{CDs}$ derivatives.

The interest in encapsulating molecules in CDs, especially for industries that are planning in encapsulating a particular active ingredient, comes from a combination of factors: ${ }^{10}$ it increases the solubility of hydrophobic species in water; it modifies the molecule spectral properties (UV-Vis spectral absorption, fluorescence, nuclear magnetic resonance (NMR), circular dichroism, etc.); ${ }^{11-13}$ decreases its reactivity, increasing stability; changes chromatographic mobility due to the difference in solubility of the complex (encapsulate molecules) when in contact with free molecules; decreases the volatilization and diffusion (in the case of volatile species), etc. When the complex formation is manifested by significant changes, as the decrease in absorbance when varying the concentration of cyclodextrin while keeping the guest concentration constant, the stability constant value can be determined using Benesi-Hildebrand equation. ${ }^{14}$ However, the factors responsible for these changes in the spectrum are not detected experimentally.

The simulation of UV-Visible spectra by computational chemistry tools is particularly appealing since modern approaches are able to provide results with an accuracy comparable to that obtained in experiments. In this sense, there are methods based on time-dependent density functional theory (TD-DFT), ${ }^{15}$ and configuration interaction singles (CIS), and both approaches provide accurate results for the electronic excitation energies. ${ }^{16}$

The use of the calculations methods such as ab initio or density functional theory (DFT) on the totality of the inclusion complex would be computationally expensive because this system consists of 160 atoms. Therefore, the use of a hybrid ONIOM method, ${ }^{17-20}$ which means "our own N-layer integrated molecular orbital and molecular mechanics", appears to be a promising strategy. The ONIOM method allows the partition of the molecular system in N-layers, where each level (or layer) is treated with a specific Hamiltonian. Integrating the results obtained at each level produces an extrapolation, so more accurate energy values are obtained for the entire system.

The ONIOM method, with different approaches, has been successfully employed in the calculation of structural parameters and energy of inclusion complexes with CDs. That, allied with experimental techniques, has been able to describe the properties of these systems. ${ }^{21,22}$

Within this framework, the goal of this research was to investigate the possibility of forming an inclusion complex (IC) of BZB with $\beta-C D$ and then to prepare and characterize the BZB @ $\beta$-CD complex. This inclusion process, between the drug $B Z B$ and $\beta-C D$, was studied both experimentally and theoretically. The ONIOM approach was employed, using TD-DFT and CIS on the study of the absorption spectrum of IC formed by the two fragments (BZB and $\beta-C D)$.

\section{Experimental}

Preparation of the inclusion complex and physical mixture

The physical mixture (PM) was prepared by gently mixing equal molar amounts of BZB (purchased from DEG, São Paulo, Brazil) and $\beta$-CD powder (Cavamax W7 from Wacker Chemie AG, Munich, Germany) during two minutes in an agate mortar and pestle. Both BZB and $\beta-C D$ were of pharmaceutical grade. The preparation of the IC was done using the coprecipitation method/lyophilization. ${ }^{6,23,24}$ BZB was dissolved in ethanol P.A. (from LabSynth, Diadema, Brazil) (0.373 g in $13 \mathrm{~mL}$ of ethanol) and added to a $\beta$-CD solution $(1 \mathrm{~g}$ in $60 \mathrm{~mL}$ of phosphate buffer $\mathrm{pH} 7.4$, $\left.50 \mathrm{mmol} \mathrm{L}^{-1}\right)$. The mixture was stirred for $24 \mathrm{~h}$ at $25^{\circ} \mathrm{C}$. The solution was then placed in a rotary evaporator (RME111, Büchi) to remove all the solvent, resulting in a solid sample in the flask. The sample was then lyophilized (FTS System, Flex Dry) for $48 \mathrm{~h}$ to obtain the material in a fine powder form, which was kept in a desiccator.

\section{Solubility diagram}

A calibration curve for BZB was done in duplicate, using a UV-Vis spectrophotometer (Varian Cary 50), at $25^{\circ} \mathrm{C}$. In a $2 \mathrm{~mL}$ of phosphate buffer $\left(\mathrm{pH} 7.4 ; 50 \mathrm{mmol} \mathrm{L}^{-1}\right)$, it was added aliquots of $15 \mathrm{~mL}$ of BZB alcoholic solution $\left(1,180 \mathrm{mmol} \mathrm{L}^{-1}\right)$. The final BZB concentrations (8.784; $17.438 ; 25.966 ; 34.369 ; 42.651 ; 50.813 \mathrm{mmol} \mathrm{L}^{-1}$ ) were 
corrected by the total volume of the solutions. ${ }^{25-27}$ BZB has two absorption bands and the one used in this study was the one whose maximum occurs at $355 \mathrm{~nm}$. The absorbance of each solution (at $355 \mathrm{~nm}$ ), in duplicate, was plotted against the concentration of BZB, and then, from a linear regression fit, the calibration curve equation was obtained.

After that, solubility tests were performed, in triplicate, at $25{ }^{\circ} \mathrm{C}$. BZB excess was added $(10 \mathrm{mg})$ to a test tube, in concentrations of $0 ; 2 ; 4 ; 6 ; 8 ; 10 ; 12 \mathrm{mmol} \mathrm{L}^{-1}$ of $\beta$-CD in phosphate buffer ( $\left.\mathrm{pH} 7.4,50 \mathrm{mmol} \mathrm{L}^{-1}\right)$ while stirring (Phonex, PA 22) for $24 \mathrm{~h}$. The concentration of the BZB solution was periodically measured using UV-Vis spectrophotometry until the absorbance was constant to assure that the equilibrium condition was reached. Then the samples were centrifuged at 3,500 rpm for $30 \mathrm{~min}$ (Fanem, Lofty II) and the supernatant drug concentration after dilution ( $30 \mu \mathrm{L}$ in $2 \mathrm{~mL}$ phosphate buffer at $\mathrm{pH} 7.4,50 \mathrm{mmol} \mathrm{L}^{-1}$ ) was determined spectrophotometrically at ca. $355 \mathrm{~nm}$. The BZB concentration obtained in the tubes was plotted compared to the concentration of $\mathrm{CD}$ (Higuchi diagram). ${ }^{28}$

\section{Stoichiometry of the IC (BZB@ $\beta-C D)$ (Job chart)}

Equimolar solutions $\left(35 \mu \mathrm{mol} \mathrm{L}{ }^{-1}\right)$ of BZB and $\beta-C D$ were prepared in phosphate buffer $\left(\mathrm{pH} 7.4,50 \mathrm{mmol} \mathrm{L}^{-1}\right)$. The molar ratios used were $0,0.2,0.33,0.5,0.67,0.8,1$. The stoichiometry was determined by mixing specific volumes of these solutions (varying the mole fraction of the $\beta$-CD and BZB species) so that the total concentration would remain constant $\left(35 \mu \mathrm{mol} \mathrm{L} \mathrm{L}^{-1}\right)$. This experiment was done in triplicate. After sample preparation, the sample was left under stirring for $24 \mathrm{~h}$ so that complexation could occur. Then it was analyzed by UV-Vis spectroscopy. The Job plot method for determining the stoichiometry of inclusion complexes is based in the continuous variation of some property (as absorbance) of the drug when using different molar concentrations of the drug and $\beta-\mathrm{CD}$. In this method, the sum of the molar concentrations of the guest (drug) and host ( $\beta$-CD) molecules is held constant while the mole fractions of both are varied. The point where the derivative of the curve was zero corresponded to the molecular stoichiometric ratio of the complex..$^{29}$

Determination of the IC association constant and fluorescence thermodynamic parameters (Scatchard plot)

To assess the suppression of the drug fluorescence due to its own concentration, solutions were prepared in phosphate buffer ( $\mathrm{pH} 7.4,50 \mathrm{mmol} \mathrm{L}^{-1}$ ) at different concentrations (4.3; 8.6; 12.8; 17.0; 21.2; 25.4; 29.5; $\left.33.0 \mathrm{mmol} \mathrm{L}^{-1}\right)$ of BZB and the fluorescence was measured using the following conditions: $\lambda$ excitation at $330 \mathrm{~nm}$; spectral range of 385-640 nm; excitation and emission slits of $10 \mathrm{~nm}$; scan speed of $600 \mathrm{~nm} \mathrm{~min}^{-1}$.

After that, samples were prepared, in triplicate, in test tubes, where the $\mathrm{CD}$ concentration ranged from 0 to $12 \mathrm{mmol} \mathrm{L}^{-1}$ and the concentration of BZB remained constant at $17.1 \mu \mathrm{mol} \mathrm{L} \mathrm{L}^{-1}$. The prepared solutions were stirred for one hour and thermostatized at 13, 25, and $37^{\circ} \mathrm{C}$ for at least $1 \mathrm{~h}$. The analyses were done in the Varian Cary Eclipse and PerkinElmer LS-55 spectrofluorimeters, coupled to a Peltier temperature controller, exciting at $330 \mathrm{~nm}$, using excitation and emission slits of $10 \mathrm{~nm}$, scan range of 385-640 nm, scan speed of $600 \mathrm{~nm} \mathrm{~min}{ }^{-1}$. The time for thermal stabilization in the equipment sample compartment before reading was $1 \mathrm{~min}$.

\section{Differential scanning calorimetry (DSC) analysis}

The individual components (BZB, $\beta-\mathrm{CD}), \mathrm{PM}$ and IC were analyzed by differential scanning calorimetry (DSC) to obtain the thermal behavior of those compounds. Measurements were conducted on a DuPont Instruments 910, in which the DSC curves were recorded under an inert atmosphere (argon flow), with a heating rate of $10^{\circ} \mathrm{C} \mathrm{min}^{-1}$.

Thermal gravimetric analysis (TGA)

The individual components (BZB, $\beta-\mathrm{CD}$ ), PM and IC were analyzed by thermal gravimetric analysis (TGA) to observe the changes in physical and chemical properties as a function of increasing temperature. TGA curves were obtained using a Thermal Gravimetric Analyzer TA 2050 TGA under the following conditions: nitrogen flow, heating rate of $10{ }^{\circ} \mathrm{C} \mathrm{min}^{-1}$, heating range of $25-500{ }^{\circ} \mathrm{C}$.

\section{X-ray diffraction $(\mathrm{XRD})$}

The individual components (BZB, $\beta-\mathrm{CD}), \mathrm{PM}$ and IC were analyzed by X-ray diffraction (XRD) to get information on the cristallinity of the samples. XRD analyses were conducted on a Shimadzu XRD 700 equipment and the XRD diffractograms were obtained with the following conditions: powder samples; radiation source $\mathrm{Cu} \mathrm{K} \alpha(\lambda=1.5406 \AA)$; scan from 5 to $50^{\circ}$; scan speed of $2^{\circ} \min ^{-1} ; 40 \mathrm{kV} ; 30 \mathrm{~mA}$.

\section{Computational methodology}

\section{Quantum chemical calculations}

The proposed model for the inclusion process is the approximation of the drug, having as a reference the atom 
shown in Figure 2, to the center of mass of the $\beta$-CD. The BZB molecule (in deprotonated form) was moved across the $\beta$-CD cavity in the $+z$ to $-z$ direction. The distance between the $\mathrm{BZB}$ and the $\beta$-CD ranged from -12 to $12 \AA$ at $1 \AA$ interval steps. Additionally, taking into consideration the rotation of the BZB molecule, represented by the $\theta$ angle, it was placed in a $y z$ plane and rotated counter-clockwise around the $z$-axis from to 0 to $300^{\circ}$ at $10^{\circ}$ intervals. As CD complexes are known to have a number of local minima, a variety of orientations were fully optimized using the semiempirical approach (PM6). The polarizable continuum model (PCM) was employed to describe the solvent effects. Hence it was possible to get all structures and respective energies of the inclusion process.
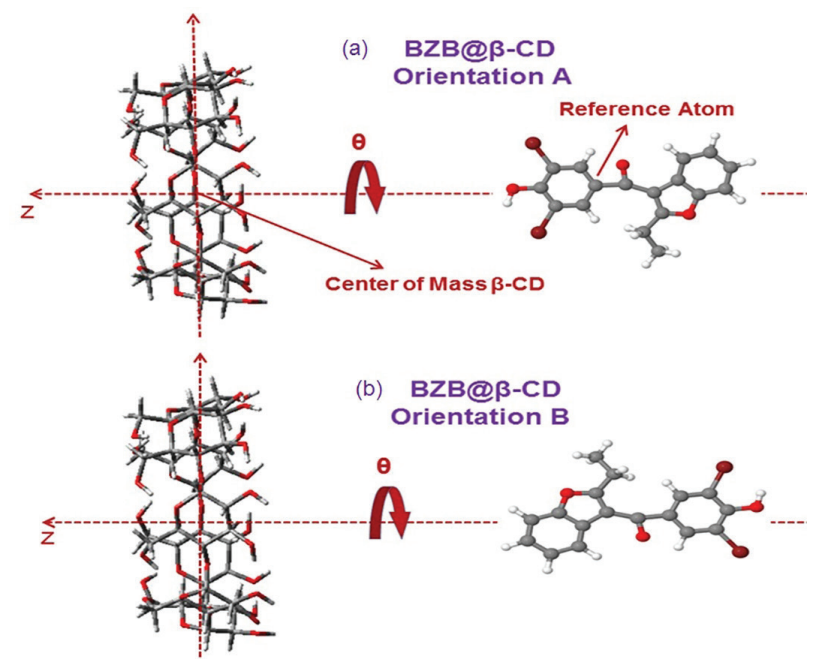

Figure 2. Encapsulation process between host ( $\beta-C D)$ and guest (BZB in neutral form) molecules along the $z$-axis, observing preferential orientation, (a) A or (b) B.

Two possibilities of inclusion were considered, one in which the approach took place via the phenolic ring substituted with bromine atoms ('A' orientation), and another in which the inclusion occurred via the aromatic ring ('B' orientation) (Figure 2). The complexation energy $\left(\mathrm{E}_{\text {complex }}\right)$ allowed us to evaluate the inclusion process and find the most stable structures among all the configurations studied. The complexation energies were calculated according to the distances and rotation angles between the BZB and the $\beta-\mathrm{CD}$ molecules considered in both orientations. It was evaluated as:

$\mathrm{E}_{\text {complex }}=\mathrm{E}_{\mathrm{BZB} @ \beta-\mathrm{CD}}-\left(\mathrm{E}_{\mathrm{BZB}}+\mathrm{E}_{\beta-\mathrm{CD}}\right)$

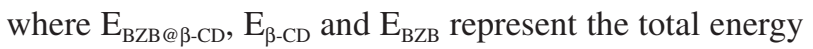
of the complex, the free optimized $\beta-C D$ energy and the free optimized BZB energy, respectively.

The electronic spectra were calculated at CIS high level method, together with the ONIOM method. In addition, a theoretical method has been developed and applied and its validation was considered on the basis of experimental results available for the system BZB @ $\beta-C D$. The ONIOM(TD-B97D:PM6) method was selected, considering that this approach led to the best results in the description of the electronic spectra in the validation process.

The ONIOM is a multilevel extrapolation method in which the studied molecular system is divided into two or more parts or layers. It is very effective for investigating inclusion complexes of CDs with guests. The most important layer from the chemical point of view is treated at a higher level of ab initio molecular orbital method. The rest of the system is described by a less demanding computational method such as lower ab initio approximations or semiempirical approximations. In the present work, the BZB@ $\beta$-CD model was divided into two layers. The high level layer, formed by the BZB, was treated with the CIS method. The low level layer, formed by the rest of the model system, that is the $\beta-C D$, was treated by PM6. The two layers are connected by hydrogen bonded link atoms.

In the terminology of Maseras and Morokuma, ${ }^{19}$ the full system is called "real", and is treated with a low level of theory. The inner layer is termed "model" and is treated with both the low and high level of theory. The total ONIOM energy $\left(\mathrm{E}^{\mathrm{ONIOM}}\right)$ is then given by the equation 2 :

$\mathrm{E}^{\mathrm{ONIOM}}=\mathrm{E}_{\text {high,model }}+\mathrm{E}_{\text {low,real }}-\mathrm{E}_{\text {low,model }}$

where $\mathrm{E}_{\text {high,model }}$ is the energy of the inner layer (BZB) at the high level of theory; $\mathrm{E}_{\text {low,real }}$ is the energy of the entire system at the low level of theory (the complexes); and $\mathrm{E}_{\text {low,model }}$ is the energy of the model system (outer layer: $\beta-\mathrm{CD}$ ) at the low level of theory.

Pople's basis sets, 6-311G++(d,p), were employed for $\mathrm{H}, \mathrm{O}$ and $\mathrm{C}$ atoms. Bromine atoms were described by aug-cc-pVTZ ${ }^{30}$ basis sets adapted with effective core potentials SBKJC, ${ }^{31}$ called CEP-ACCt. Finally, solvent effects were included using the $\mathrm{PCM},{ }^{32}$ and water was used as the solvent in all simulations. All calculations were performed in Gaussian 09 program package. ${ }^{33}$

The electronic spectra plotting and the normalization and half height adjustments of the bands of these spectra were carried with Gabedit software. ${ }^{34}$

\section{Results and Discussion}

Solubility diagram

In the calibration curve, it was possible to observe that the absorbance had a linear response to the concentration 
(linear correlation coefficient, $\mathrm{R}^{2}=0.999$ ). From the linear regression fit, the following calibration curve equation was obtained: $y=-0.00644+20,104 x$, where $y=$ absorbance; $x=$ molar concentration of BZB. The slope corresponds to the molar absorptivity of BZB in phosphate buffer ( $\mathrm{pH} 7.4)$, which is $20,104 \mathrm{~L} \mathrm{~mol}^{-1} \mathrm{~cm}^{-1}$.

The solubility studies were then performed, in triplicate, at $25^{\circ} \mathrm{C}$, according to the method described by Higuchi and Connors, ${ }^{35}$ in order to determine the stability constant of the complex BZB@ $\beta$-CD and evaluate its molecular stoichiometry.

Initially, the solubility tests were performed with the drug and $\beta-\mathrm{CD}$ both dissolved in deionized water (pH 7, as measured). However, this analysis did not show reproducibility as the intensities of the absorption bands between the duplicates and triplicates oscillated constantly. Although the $\mathrm{p} K_{\mathrm{a}}$ of BZB is $4.5,{ }^{36}$ a molecule portion will be ionized (phenolate ions) and, therefore, complexation of the ionized portion of the BZB will be different from the non-ionized portion of the BZB. Another test was performed using a citrate buffer $(\mathrm{pH} 3)$, but little variation in the absorption intensity was observed between the BZB solution in this buffer and the BZB with $\beta$-CD solution in the same buffer. All experimental work was done at $\mathrm{pH} 7.4$ and since BZB has a $\mathrm{p} K_{\mathrm{a}}=4.5$, the drug exists predominantly as the deprotonated phenolate form. So, all theoretical calculations were performed on this form. According to Locuson et al. ${ }^{36}$ the presence of halogens near the phenol ring increases the lipophilicity of the molecule, as well as acylation of phenol decreases lipophilicity. Therefore, the solubility test and all experiments made in this study were performed using this phosphate buffer.

The concentrations of BZB were plotted as a function of $\beta$-CD concentrations to obtain the solubility diagram (Figure 3a). This figure shows the monotonic increase of solubilization of BZB with the $\beta-\mathrm{CD}$ concentration and Figure $3 b$ shows the UV-Vis absorption spectra of one of the BZB with $\beta$-CD replicates solutions. One can observe an increase in the BZB absorbance at increasing of $\beta-C D$ concentration, which can suggest IC formation.

From the linear portion of the plot (Figure 3a), it was possible to obtain the stability constant or the complex formation constant $(\mathrm{K})$ using the Higuchi-Connors ${ }^{35}$ equation (equation 3 ):

$$
\mathrm{K}=\frac{\mathrm{a}}{\mathrm{b} \times(1-\mathrm{a})}
$$

The equation for the linear part of the plot is: $y=1.021 \times 10^{-4}+0.21637 x$ and $\mathrm{R}^{2}=0.998$, where a is the slope and $b$ the intercept of the Higuchi-Connors solubility linear plot. ${ }^{35,37}$ It is possible to say that BZB forms a soluble complex with $\beta-C D$; furthermore, the stoichiometry appears to be $1: 1$, and the concentration of $\beta-\mathrm{CD}$ is $8 \mathrm{mmol} \mathrm{L}^{-1}$. Applying the equation 3 it was possible to obtain the stability constant $\left(2,119 \mathrm{~L} \mathrm{~mol}^{-1}\right)$ indicating a strong interaction between the host $(\beta-C D)$ and the guest (BZB). The apparent solubility of BZB in water, in the absence of cyclodextrin, was determined directly by the linear coefficient resulting in $43.3 \mathrm{mg} \mathrm{L}^{-1}$.

\section{Stoichiometry of the complex BZB in $\beta$-CD (Job plot)}

The continuous variation method (Job method) was used to determine/confirm the molecular stoichiometry of the IC. ${ }^{38}$ This method is based on the continuous variation of a drug property (in this case the fluorescence intensity) in the presence of different molar concentrations of the drug/cyclodextrin. In this method the molar concentration of the two species is constant at $35 \mu \mathrm{mol} \mathrm{L} \mathrm{L}^{-1}$ and the molar fraction of the drug varies from 0 to 1 .

The Job plot (Figure 4) has a maximum at mole fraction $(r)=0.5$, indicating that the complex BZB @ $\beta-C D$ has a stoichiometric proportion of $1: 1$, which means an association of 1 molecule of $\beta$-CD with 1 molecule of
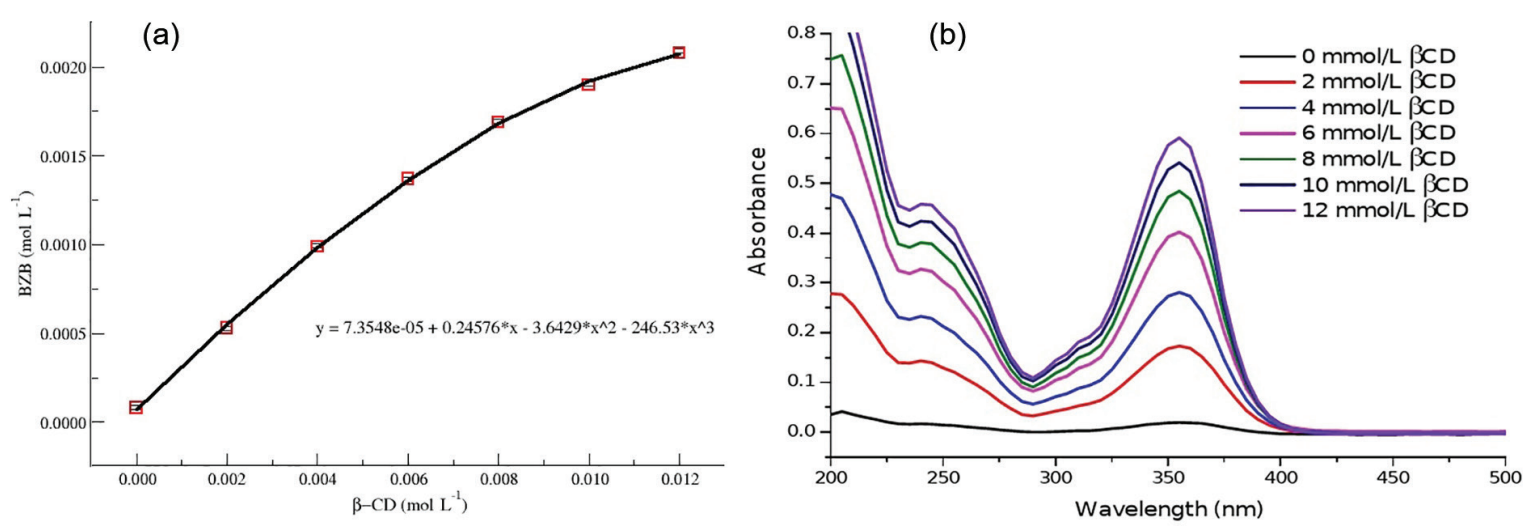

Figure 3. (a) Phase solubility diagram for BZB in the presence of $\beta-\mathrm{CD}$, at $25^{\circ} \mathrm{C}$; (b) UV-Vis spectra of solutions of BZB complexed with different concentrations of $\beta-C D$. 
BZB. These results are in agreement with the stoichiometry suggested in the study of the solubility diagram.

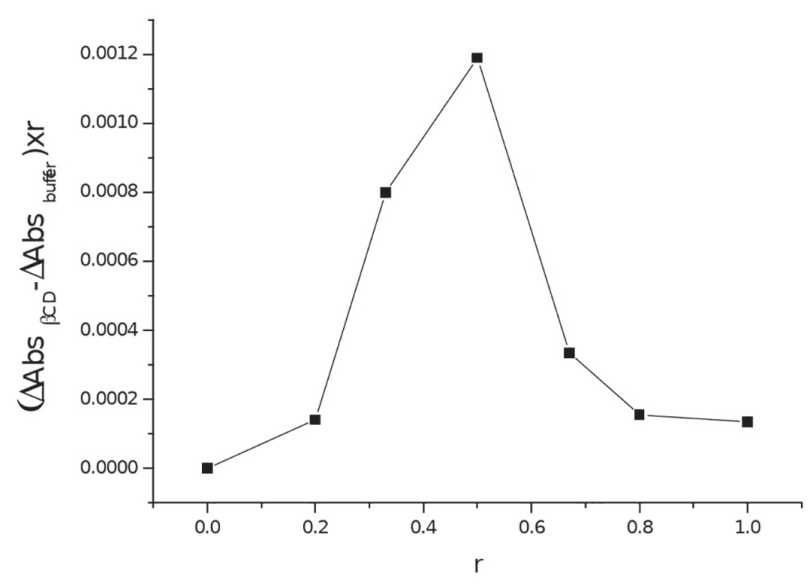

Figure 4. Job plot.

BZB@ $\beta-C D$ association constant and thermodynamic parameters as determined from fluorescence spectra (Scatchard plot)

The fluorescence intensity of BZB as a function of its concentration was monitored to determine the linear concentration region, in which there is no suppression of the emission intensity by excess of drugs molecules. The fluorescence intensity has a linear response until the BZB concentration reach $17.1 \mu \mathrm{mol} \mathrm{L} \mathrm{L}^{-1}$, which was the used concentration on the Scatchard test. The BZB fluorescence spectra (at one given concentration) was monitored as a function of different temperatures (at 13,25 and $37^{\circ} \mathrm{C}$ ) (Figure 5a). The BZB fluorescence spectra at $25^{\circ} \mathrm{C}$ is in Figure $5 \mathrm{~b}$ and the curves obtained considering the BZB emission $\lambda_{\max }(429 \mathrm{~nm}$ ) on each $\beta$-CD concentration, for each temperature, are presented in Figure 5a. An increase

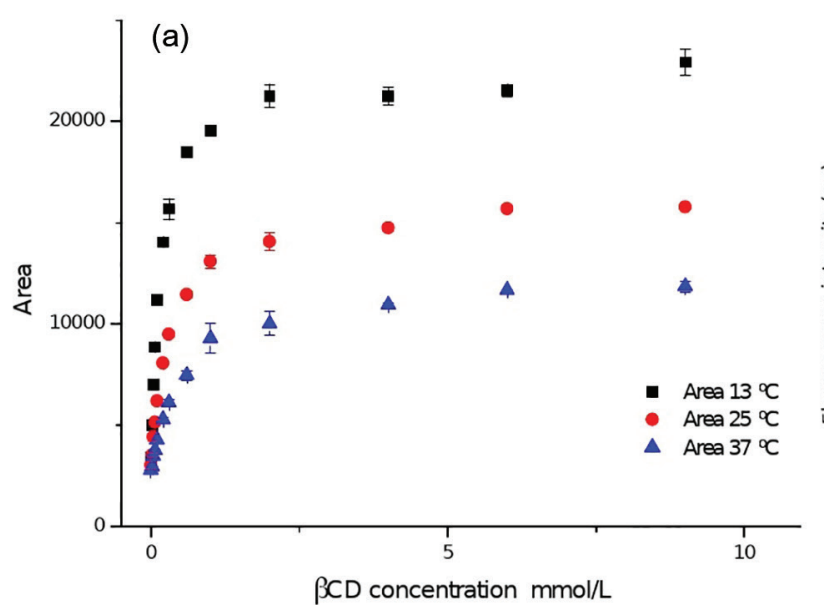

in BZB fluorescence intensity can be observed as the concentrations of $C D$ were increased, suggesting the formation of the IC (BZB@ $\beta-C D)$.

The temperature effect in the BZB fluorescence can be visualized in Figure 5a. It is possible to notice that as the temperature was raised, the fluorescence decreased due to the increased collisions between molecules.

The relationship between the change in the intensity of the BZB fluorescence band at $428 \mathrm{~nm}$ and the $\beta-\mathrm{CD}$ concentration gives the association constant through equation $4 .{ }^{39}$ The plot of $\left(\mathrm{I}-\mathrm{I}_{\mathrm{o}}\right)$ / [CD] as a function of $\left(I-I_{0}\right)$ allows the calculation of the association constant.

$\frac{\mathrm{I}-\mathrm{I}_{\mathrm{o}}}{[\mathrm{CD}]}=\left(\mathrm{I}_{\infty}-\mathrm{I}_{\mathrm{o}}\right) \mathrm{K}-\left(\mathrm{I}-\mathrm{I}_{\mathrm{o}}\right) \mathrm{K}=\left(\mathrm{I}_{\infty}-\mathrm{I}\right) \mathrm{K}$

where $I_{0}$ is the BZB fluorescence band intensity in the absence of $\beta-C D ;[\beta-C D]$ is the $\beta-C D$ concentration in each titration point; $I_{\infty}$ is the fluorescence band intensity when each $\mathrm{BZB}$ molecule is complexed by $\beta-\mathrm{CD}$ (i.e., BZB with $C D$ excess); I is fluorescence band intensity observed in each titration point; $\mathrm{K}$ is the association constant (in $\mathrm{L} \mathrm{mol}^{-1}$ ).

Figure 6a shows the Scatchard plot using the fluorescence intensities at $25{ }^{\circ} \mathrm{C}$, and it suggests the stoichiometry of the complex as $1: 1$. The association constants were calculated in each temperature using the Scatchard equation (equation 4). It is possible to see that the values of this constant decrease with the increase of the temperature (Table 1), which is expected, since the increase in temperature favors the dissociation of the IC.

The thermodynamic parameters Gibbs free energy $(\Delta \mathrm{G})$, enthalpy $(\Delta \mathrm{H})$ and entropy $(\Delta \mathrm{S})$ for the BZB $@ \beta-C D$ complex were obtained from the van't Hoff equation $\left(\operatorname{lnK}=-\frac{\Delta \mathrm{H}}{\mathrm{RT}}+\frac{\Delta \mathrm{S}}{\mathrm{R}}\right)$ estimating the constant in different

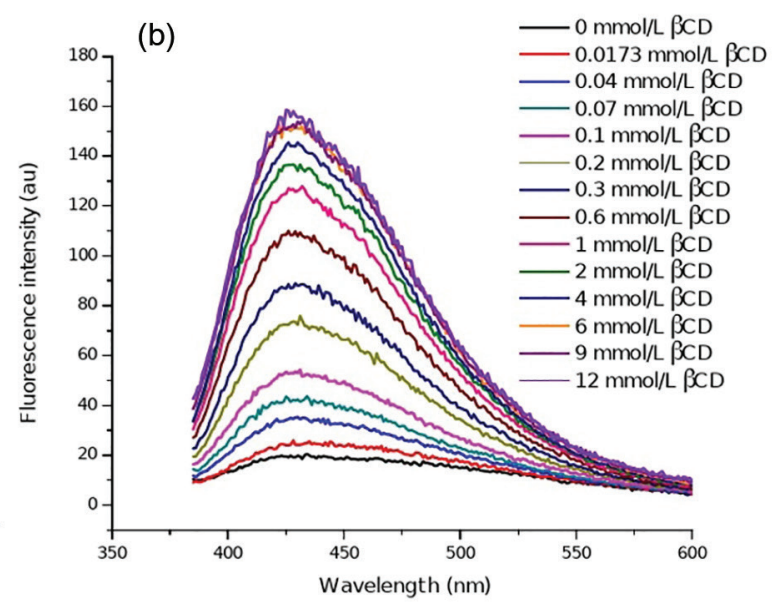

Figure 5. (a) BZB fluorescence intensity in the presence of increasing concentrations of $\beta-\mathrm{CD}$ at 13,25 and $37^{\circ} \mathrm{C}$ and (b) BZB fluorescence spectra at different $\beta$-CD concentrations at $25^{\circ} \mathrm{C}$. 

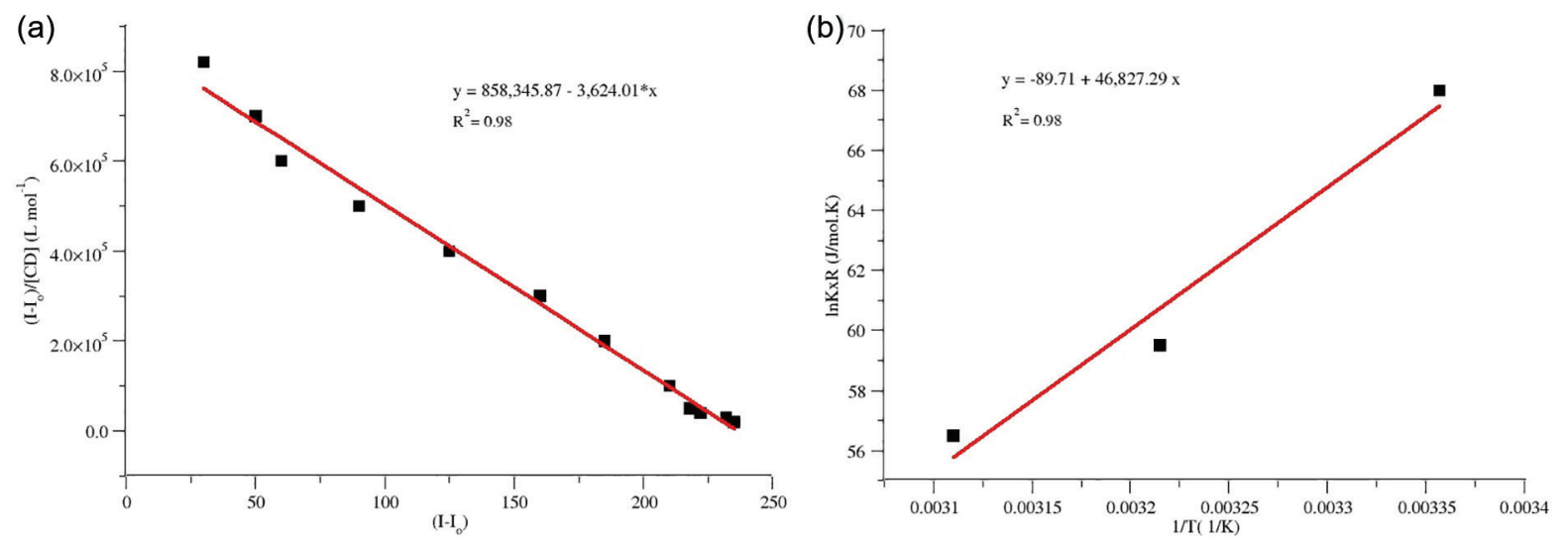

Figure 6. (a) Scatchard plot for BZB fluorescence measurements at $25^{\circ} \mathrm{C}$; (b) plot of $\ln \mathrm{K} \times \mathrm{R}$ as a function of $\mathrm{T}^{-1}$ (van't Hoff equation).

Table 1. Complex formation constant $(\mathrm{K})$, Gibbs free energy $(\Delta \mathrm{G})$, enthalpy $(\Delta \mathrm{H})$, and entropy $(\Delta \mathrm{S})$ of $\beta-\mathrm{CD}$ complex at different temperatures

\begin{tabular}{lccc}
\hline & $13{ }^{\circ} \mathrm{C}$ & $25^{\circ} \mathrm{C}$ & $37^{\circ} \mathrm{C}$ \\
\hline $\mathrm{K}$ (Scatchard) / $\left(\mathrm{L} \mathrm{mol}^{-1}\right)$ & 3,624 & 1,341 & 892 \\
$\Delta \mathrm{G} \mathrm{/}\left(\mathrm{kJ} \mathrm{mol}^{-1}\right)$ & -20.1 & -19.0 & -17.9 \\
$\Delta \mathrm{H} /\left(\mathrm{kJ} \mathrm{mol}^{-1}\right)$ & -46.8 & - & - \\
$\Delta \mathrm{S} /\left(\mathrm{J} \mathrm{mol}^{-1} \mathrm{~K}^{-1}\right)$ & -89.7 & - & - \\
\hline
\end{tabular}

temperatures $\left(13,25\right.$ and $\left.37^{\circ} \mathrm{C}\right)$. The $\Delta \mathrm{H}$ and $\Delta \mathrm{S}$ values were calculated from the angle and intercept of the plot $(\ln K \times \mathrm{R})$ as a function of $\mathrm{T}^{-1}$, respectively (Figure $6 \mathrm{~b}$ ). The value of $\Delta \mathrm{G}$ was obtained from the equation: $\Delta \mathrm{G}=\Delta \mathrm{H}-\mathrm{T} \Delta \mathrm{S}$. The values of the calculated thermodynamic parameters are in Table 1.

According to Alvariza and co-workers ${ }^{40}$ and Jullian et al. ${ }^{41}$ the $\Delta \mathrm{H}$ negative value is typical of hydrophobic molecules which complexation is favored by the attractive interaction of van der Waals forces between host and guest and/or the presence of intermolecular hydrogen bonds. Negative $\Delta \mathrm{S}$ values usually describe guest molecules unable of totally penetrating inside the cyclodextrin cavity and/or that the encapsulation is prevented by strong interactions with the external surface of the rigid $C D$ molecule. The formation of the BZB@ $\beta$-CD inclusion complex was an enthalpy driven process and the negative value of $\Delta \mathrm{G}$ indicated spontaneous formation of the IC in aqueous solution.

\section{DSC analysis of BZB, $\beta-C D, P M$, and IC}

The DSC curves for BZB, $\beta-C D, P M$, and IC are presented in Figure 7. The calorimetric curve for pure BZB shows a narrow endothermic peak with minumum at $155^{\circ} \mathrm{C}$ corresponding to its melt temperature. The small width of this peak indicates the high purity of the BZB sample. The $\beta$-CD DSC curve shows a wide endothermic peak between

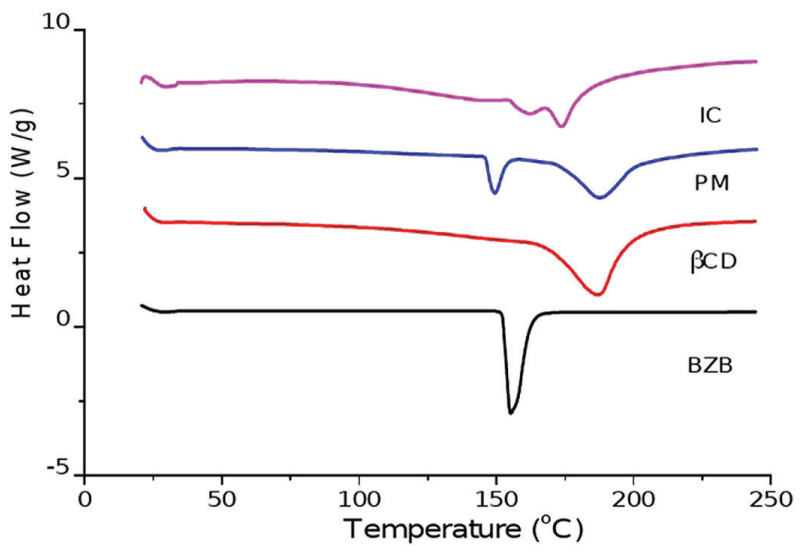

Figure 7. DSC curves of BZB, $\beta-C D, P M$, and IC.

100 and $225^{\circ} \mathrm{C}$. This broad peak indicates that the water molecules associated with $\beta$-CD comes from more than one source, namely the water molecules inside the CD cavity, the ones associated, through hydrogen interactions, with the $\mathrm{OH}$ groups of the $\mathrm{C} 2$ and $\mathrm{C} 3$ glucopyranose units in the larger border and the $\mathrm{OH}$ groups of the $\mathrm{C} 6$ glucopyranose units in the small border of the CD molecules. The PM DSC curve is a combination of the curves from isolated BZB and $\beta-C D$, showing only small shifts toward lower (BZB) and higher $(\beta-C D)$ temperature. This behavior indicates physical interactions, but no complexation, between these molecules. Finally the DSC curve for the inclusion complex shows more pronounced changes: (i) a decrease in the intensity of both peaks; (ii) shifts in the opposite direction of that of the PM, i.e., a decrease in the melt temperature for BZB and $\beta-C D$, and (iii) an increase in the width of the peak for BZB and a decrease in the peak for $\beta-C D$, indicating stronger interactions between these molecules and suggesting encapsulation of BZB by $\beta-\mathrm{CD}$.

TGA analysis of BZB, $\beta-C D, P M$, and IC

Figure 8 shows the TGA curves for BZB, $\beta$-CD, PM, 
and IC. The TGA for $\beta-\mathrm{CD}$ shows 2 steps of mass loss. The first one (14\%), between 30 and $90{ }^{\circ} \mathrm{C}$, due to water molecules inside the $\beta$-CD hydrophobic cavity and the second between 300 and $400{ }^{\circ} \mathrm{C}$, due to decomposition of the sample. BZB shows only one mass loss, from 250 to $324^{\circ} \mathrm{C}$, due to its decomposition. PM shows three steps: (i) the first one, between 30 and $100{ }^{\circ} \mathrm{C}$, due to water loss from inside the $\beta$-CD cavity, (ii) the second, between 100 and $260{ }^{\circ} \mathrm{C}$, due to BZB decomposition; and (iii) the last, between 260 and $400{ }^{\circ} \mathrm{C}$, due to $\beta$-CD degradation. It is worth to note that all these temperatures were different from those of the pure compounds, indicating that even in the PM there are interactions between the guest and host. The TGA curve for the IC is different from that of the PM, showing 2 steps of mass loss: (i) one up to ca. $75^{\circ} \mathrm{C}$, lower than that of the PM, related to water loss, and (ii) the second at ca. $275^{\circ} \mathrm{C}$, due to IC decomposition. It is observed that the water loss from PM is smaller than that of the IC suggesting that the water molecule interactions in PM are stronger. Also the temperature gap between the water loss and the IC degradation is larger than that of the PM indicating that the IC is more stable than the PM.

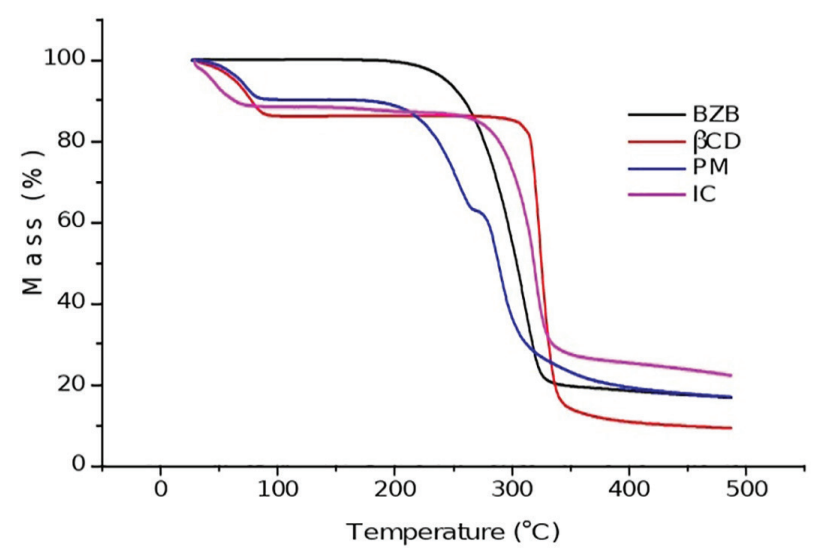

Figure 8. TGA curves for BZB, $\beta-\mathrm{CD}$, PM, and IC.

\section{XRD complexation analysis}

The IC formation generally results in changes in the $\mathrm{CD}$ and guest molecule X-ray diffraction patterns, due to sample amorphization (reduced crystallinity) and disappearance of X-ray CD characteristic peaks, appearance and/or widening of the peaks. X-ray diffraction can provide an indirect evidence for complex formation, since the drug's crystal structure is destroyed under complexation. The X-ray diffractograms of BZB, $\beta-C D$, $\mathrm{PM}$ and IC are shown in Figure 9. It was possible to observe that pure BZB and $\beta$-CD have diffraction patterns that characterizes a crystalline structure; furthermore the PM $\mathrm{X}$-ray diffractogram corresponded to the mixture of these two patterns. For the IC the X-ray diffraction pattern is very different from that of the PM, showing that the intensities and number of peaks are strongly reduced, again suggesting amorphization of the sample.

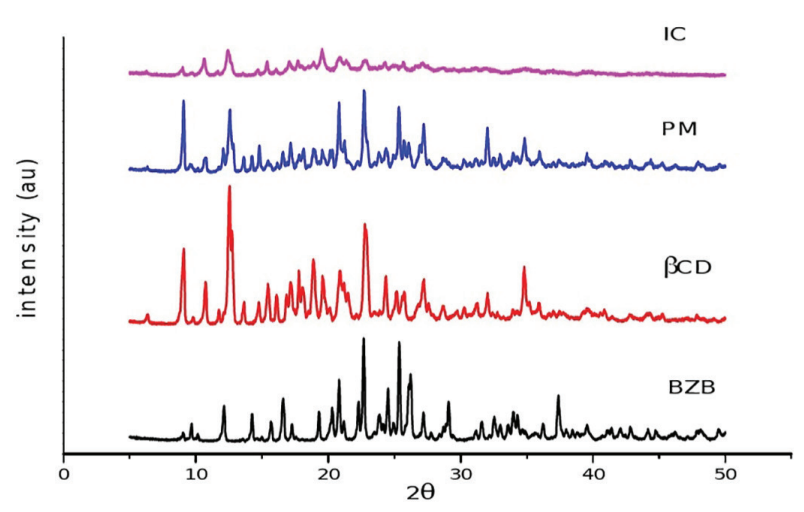

Figure 9. X-ray diffractograms of BZB, $\beta-\mathrm{CD}$, PM, and IC.

Electronic energies and structures of the inclusion complexes

The full analysis of the inclusion process was carried out considering an energy map. The maps show the energy for each combination of angle $(\theta)$ and $z$ coordinate of the inclusion process. The energies were computed at the PM6 level of theory (Figure 10).

Figure 10a represents the results of ' $A$ ' and ' $B$ ' orientations. The first remark to be made is that some complexation energies are negative which demonstrates that the inclusion process of BZB into $\beta-C D$ is energetically favorable. Second, the maps show several local minima, where the energy minimum is ranging from -10.20 to $-10.48 \mathrm{kcal} \mathrm{mol}^{-1}$, represented by the red regions on the energy maps. The geometric parameters of the minima and their respective energies of complexation obtained with the PM6 level are shown in Table 2.

Since these structures are representative of the various possibilities of the inclusion process, it ensures that there is a balance between all possibilities studied. This equilibrium distribution mainly arises because the inclusion complexes are formed by various non covalent interactions and thus the formation of multiple equilibria in these types of systems is expected. ${ }^{42,43}$ For this purpose, the equation 5 is applied, as a first approximation, to evaluate the equilibrium distribution of each stable isomer $\left(\mathrm{P}_{\mathrm{i}}\right)$ of the six structures. ${ }^{44}$ The results are shown in Figure 11.

$\mathrm{P}_{\mathrm{i}}(\%)=\frac{\mathrm{e}^{-\Delta \mathrm{E}_{\mathrm{T}}(\mathrm{i} / \mathrm{RT}}}{\sum_{\mathrm{i}} \mathrm{e}^{-\Delta \mathrm{E}_{\mathrm{T}}(\mathrm{i}) / \mathrm{RT}}}$

where $\Delta \mathrm{E}_{\mathrm{T}}(\mathrm{i})$ is the difference between the energies of $\mathrm{i}$ 

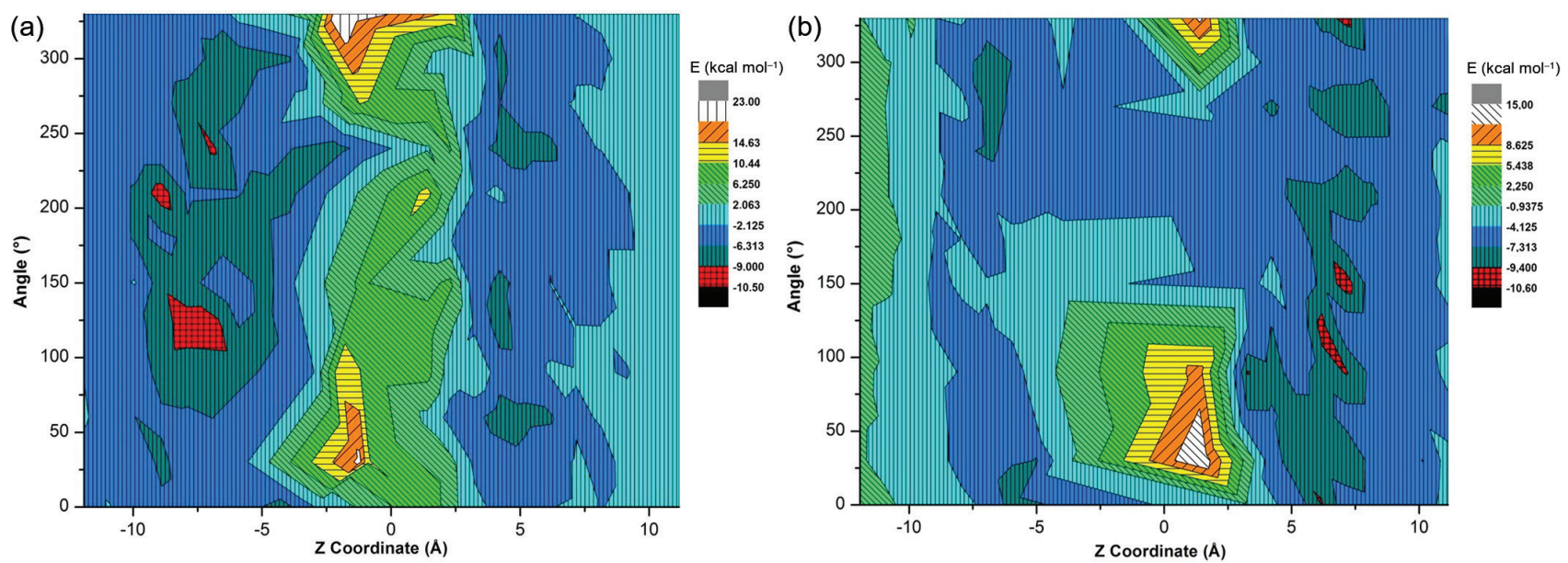

Figure 10. PM6 complexation energy maps of the inclusion process of BZB into $\beta$-CD at different positions $(z)$ and angles $(\theta)$ for both orientations.

Table 2. Complexation energies $\left(\mathrm{E}_{\text {complex }}\right)$ at the energy minimum for both orientations ( $z$-axis) and the angle rotation $(\theta)$, obtained with the semiempirical approach (PM6)

\begin{tabular}{|c|c|c|c|c|c|c|c|}
\hline \multicolumn{8}{|c|}{ Interaction mode } \\
\hline \multicolumn{4}{|c|}{ A } & \multicolumn{4}{|c|}{ B } \\
\hline Complex & $z / \AA$ & $\theta /$ degree & $\begin{array}{c}\mathrm{E}_{\text {complex }} / \\
\left(\mathrm{kcal} \mathrm{mol}^{-1}\right)\end{array}$ & Complex & $z / \AA ̊$ & $\theta /$ degree & $\begin{array}{c}\mathrm{E}_{\text {complex }} / \\
\left(\mathrm{kcal} \mathrm{mol}^{-1}\right)\end{array}$ \\
\hline $1 \mathrm{~A}$ & -8.9 & 210 & -10.355 & 1B & 6.19 & 120 & -10.200 \\
\hline $2 \mathrm{~A}$ & -7.9 & 120 & -10.352 & $2 \mathrm{~B}$ & 7.14 & 150 & -10.481 \\
\hline $3 \mathrm{~A}$ & -6.9 & 120 & -10.435 & $3 B$ & 7.14 & 330 & -10.245 \\
\hline
\end{tabular}

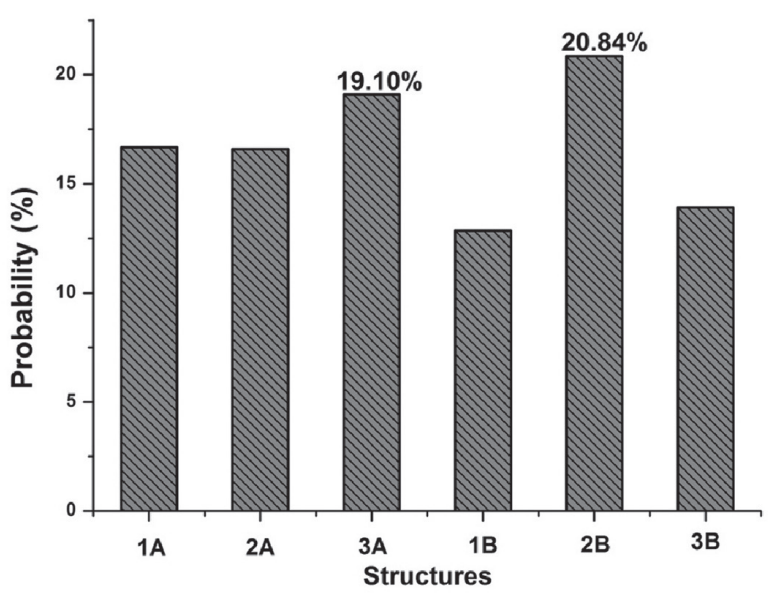

Figure 11. The equilibrium distributions of complexes BZB@ $\beta-C D$.

conformer: $(\mathrm{E}(\mathrm{i})=1 \mathrm{~A}, 2 \mathrm{~A}, \ldots 3 \mathrm{~B})$ and the conformer with the lowest energy (global minimum) at $298.15 \mathrm{~K}$ and $\mathrm{R}$ is the ideal gas constant.

Figure 11 shows the equilibrium distribution (probability, $\mathrm{P}$, in \%) of the six more stable structures (presented in Figure 12). From Figure 11, it can be seen that structure 2B has the largest probability $(20.84 \%)$ of all complexes. The $\mathrm{P}(3 \mathrm{~A})$ is $19.10 \%$ and the lower $\mathrm{P}$ are that of structures $1 \mathrm{~B}$ and $3 \mathrm{~B}, 13$ and $14 \%$, respectively.

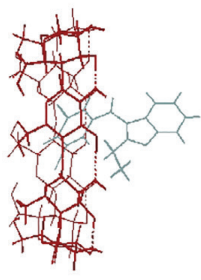

1A

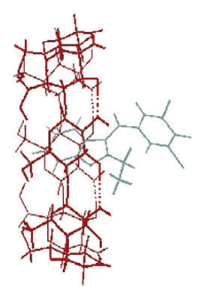

$1 \mathrm{~B}$

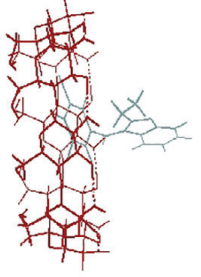

2A

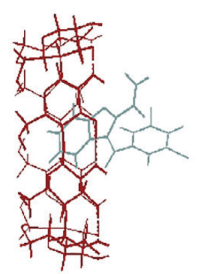

2B

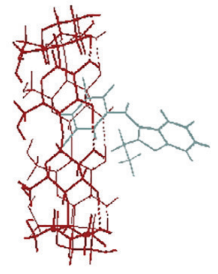

3A

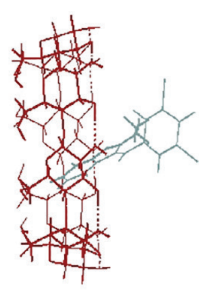

3B

Figure 12. ONIOM(TD-B97D:PM6) fully optimized structures for both interaction modes.

From these results it can be concluded that there is no structure with a major contribution to the equilibrium distribution and thus all properties depend on this distribution. In this context, the calculation of electronic spectra was based on this equilibrium distribution. The wavelength of the absorption band $\left(\lambda_{\max }\right)$ was 
calculated taking into account this distribution and using equation 6 :

$$
\lambda_{\max , \mathrm{T}}=\sum_{\mathrm{i}=1}^{6} \lambda_{\text {max }, \mathrm{i}} \mathrm{P}_{\mathrm{i}}(\%)
$$

where $\lambda_{\text {max }, \mathrm{T}}, \lambda_{\text {max }, \mathrm{i}}$ and $\mathrm{P}_{\mathrm{i}}$ are the total maximum absorption, the maximum absorption of each individual structure and its equilibrium distributions, respectively.

\section{Electronic spectra}

The UV-Vis absorption spectrum is an important tool used in the characterization of inclusion complexes. Thus, we have evaluated the performance of TD-DFT and CIS methods implemented with ONIOM, in the description of the electronic spectra of BZB and inclusion complex BZB@ $\beta-C D$. To study the BZB drug electronic spectrum TD-B97D and CIS were used, because this system contains less electrons than its inclusion complex and so there is no need to use ONIOM methodology to represent the system. The BZB UV-Vis absorption spectra are shown in Figure 13.

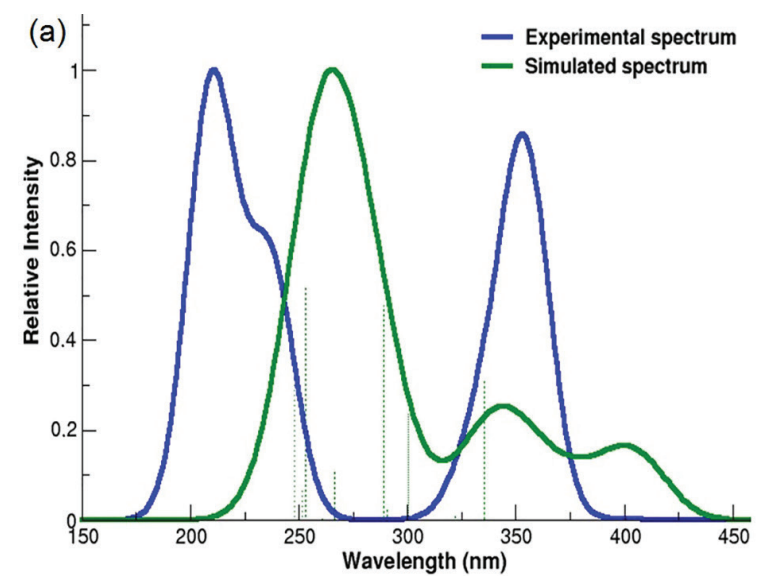

At the TD-B97D level it is possible to notice an electronic transition at $348 \mathrm{~nm}$ (Figure 13a). This result is remarkably close to the experimental measurement $(355 \mathrm{~nm})$. However, in this region of the electromagnetic spectrum, no electronic transition has been obtained with the CIS approach (Figure 13b).

The BZB @ $\beta$-CD experimental and simulated electronic absorption spectra are displayed in Figures 14a and 14b for the ONIOM(TD-B97D:PM6) and ONIOM(CIS:PM6) methods, respectively. It can be seen that the band positions and relative intensities are predicted in a satisfactory way at the CIS level, while the description of the first band with the ONIOM(TD-B97D:PM6) method was shifted $47 \mathrm{~nm}$ to the right. The position of the second absorption band is well predicted by both methodologies. With the ONIOM(CIS:PM6) approach, besides the characteristic band at $330 \mathrm{~nm}$, the appearance of a band at $186 \mathrm{~nm}$ and a shoulder at $220 \mathrm{~nm}$ can be noticed. Figures $3 \mathrm{~b}$ and $5 \mathrm{~b}$ show a shift toward shorter wavelengths with increasing BZB concentration. So the ab initio CIS method can provide a reliable prediction for the absorption spectra of the BZB@ $\beta$-CD supramolecular system, while the

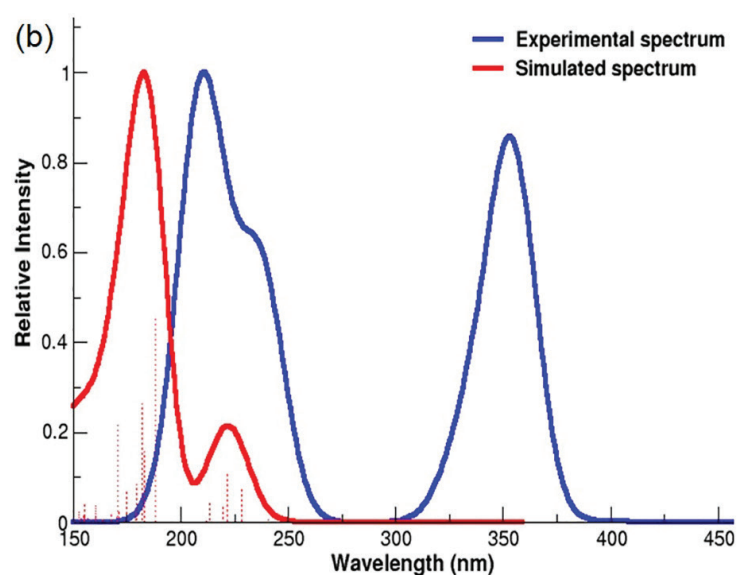

Figure 13. Experimental and simulated UV-Vis spectra of benzbromarone (BZB) by (a) ONIOM(TD-B97D:PM6); (b) ONIOM(CIS:PM6).
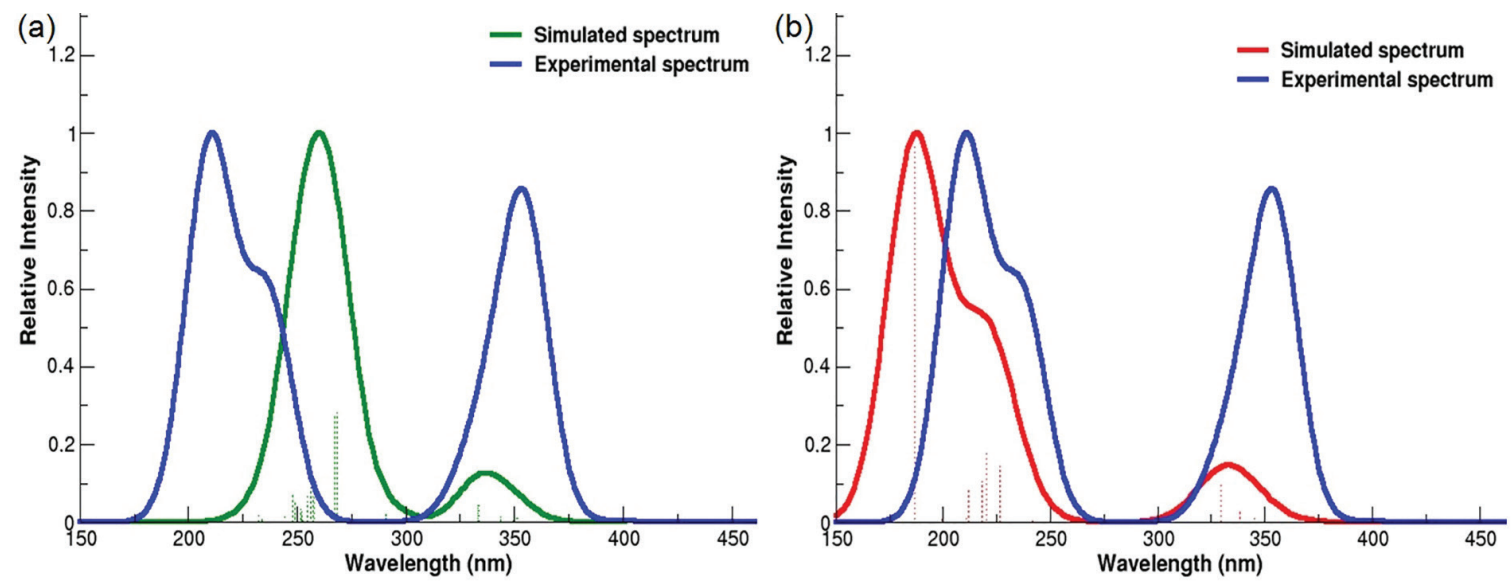

Figure 14. Experimental and simulated UV-Vis spectra of inclusion complexes BZB @ $\beta$-CD by (a) ONIOM(TD-B97D:PM6); (b) ONIOM(CIS:PM6). 
ONIOM(TD-B97D:PM6) method behaves better when applied to the uncomplexed system.

\section{Conclusions}

This work presents the preparation and physicochemical characterization data of BZB and $\beta-C D$ inclusion complex, aiming at an eventual drug production designed for oral administration, that would be different from the conventional formulation, to treat gout and other related pathologies. It was possible to prepare the $\mathrm{BZB}: \beta-\mathrm{CD}$ complex in phosphate buffer ( $\mathrm{pH}$ 7.4), with a 1:1 stoichiometry, indicating that the hydrophobic cavity of the $\beta$-CD holds only one BZB molecule or part of it. All the experimental data support that the encapsulation was successful. In an accompanying paper it will be presented NMR results for the inclusion complex and theoretical calculations to support the IC conformation and that the encapsulation process is spontaneous and enthalpically driven.

In general, the present theoretical investigation provides better insights into the structure of the BZB@ $\beta-C D$ inclusion complex. A comparative study of TD-DFT and CIS, along with ONIOM method, has been carried out on the UV-Vis absorption of BZB and their $\beta$-CD inclusion complexes. The qualitative description of the simulated spectrum, given by ONIOM(CIS:PM6), is in accord with the experimental one.

\section{Acknowledgments}

This work was supported by the Foundation of the State of São Paulo (FAPESP, grant 2013/08293-7), National Council for Scientific and Technological Development (CNPq, grant 303581/2018-2).

\section{Author Contributions}

Francisco B. T. Pessine and Nelson H. Morgon provided the idea of the present study and obtained the financial support; Kátia C. Bassani and Milene H. Martins did most of the experiments and data analysis; Iran L. Sousa and Caio M. Porto performed the theoretical calculations. All authors contributed to the analysis of the results and to the writing of the manuscript. The final version of the manuscript was done by Caio M. Porto, Francisco B. T. Pessine and Nelson H. Morgon.

\section{References}

1. Hopfinger, A. J.; Esposito, E. X.; Llinás, A.; Glen, R. C.; Goodman, J. M.; J. Chem. Inf. Model. 2009, 49, 1.
2. Kumar, S.; Ng, J.; Gow, P.; N. Z. Med. J. 2005, 118, U1528.

3. Lee, M. H.; Graham, G. G.; Williams, K. M.; Day, R. O.; Drug Safety 2008, 31, 643.

4. Eleamen, G. R. A.; da Costa, S. C.; Lima-Neto, R. G.; Neves, R. P.; Rolim, L. A.; Rolim-Neto, P. J.; Moura, R. O.; de Aquino, T. M.; Bento, E. S.; Scotti, M. T.; Mendonça-Junior, F. J. B.; Mendonça, E. A. M.; Oliveira, E. E.; J. Braz. Chem. Soc. 2017, $28,116$.

5. Fumes, B. H.; Guzzo, M. R.; Machado, A. E. H.; Okano, L. T.; J. Braz. Chem. Soc. 2016, 27, 382.

6. Frömming, K.-H.; Szejtli, J.; Cyclodextrins in Pharmacy (Topics in Inclusion Science Book 5); Springer: New York, USA, 2013.

7. Morais, W. A.; de Barros Neto, B.; Cavalcanti, I. M. F.; Xavier Jr., F. H.; Santos-Magalhães, N. S.; Maciel, M. A. M.; J. Braz. Chem. Soc. 2017, 28, 1494.

8. Abbehausen, C.; Formiga, A. L. B.; Sabadini, E.; Yoshida, I. V. P.; J. Braz. Chem. Soc. 2010, 21, 1867.

9. Szejtli, J.; Pure Appl. Chem. 2004, 76, 1825.

10. Szejtli, J.; Chem. Rev. 1998, 98, 1743.

11. Chaves, O. A.; Ferreira, R. C.; da Silva, L. S.; de Souza, B. C. E.; Cesarin-Sobrinho, D.; Netto-Ferreira, J. C.; Sant'Anna, C. M. R.; Ferreira, A. B. B.; J. Braz. Chem. Soc. 2018, 29, 1551.

12. Siva, S.; Li, C.; Cui, H.; Lin, L.; J. Mol. Liq. 2019, 296, 111777.

13. Cui, H.; Siva, S.; Lin, L.; Ultrason. Sonochem. 2019, $56,84$.

14. Wang, H. Y.; Han, J.; Feng, X. G.; Spectrochim. Acta, Part A 2007, 66, 578.

15. Runge, E.; Gross, E. K. U.; Phys. Rev. Lett. 1984, 52, 997.

16. Sonk, J. A.; Schlegel, H. B.; J. Phys. Chem. A 2011, 115, 11832.

17. Warshel, A.; Karplus, M.; J. Am. Chem. Soc. 1972, 94, 5612.

18. Warshel, A.; Levitt, M.; J. Mol. Biol. 1976, 103, 227.

19. Maseras, F.; Morokuma, K.; J. Comput. Chem. 1995, 16, 1170.

20. Svensson, M.; Humbel, S.; Froese, R. D. J.; Matsubara, T.; Sieber, S.; Morokuma, K.; J. Phys. Chem. 1996, 100, 19357.

21. Bensouilah, N.; Abdaoui, M.; C. R. Chim. 2012, 15, 1022.

22. Yahia, O. A.; Khatmi, D.; J. Mol. Struct.: THEOCHEM 2009, $912,38$.

23. Calderini, A.; Martins, M. H.; Pessine, F. B. T.; J. Inclusion Phenom. Macrocyclic Chem. 2013, 75, 77.

24. Badr-Eldin, S. M.; Elkheshen, S. A.; Ghorab, M. M.; Eur. J. Pharm. Biopharm. 2008, 70, 819.

25. Devarakonda, B.; Hill, R. A.; Liebenberg, W.; Brits, M.; de Villiers, M. M.; Int. J. Pharm. 2005, 304, 193.

26. Chen, A.; Liu, M.; Dong, L.; Sun, D.; Fluid Phase Equilib. 2013, 341, 42.

27. Liu, M.; Chen, A.; Wang, Y.; Wang, C.; Wang, B.; Sun, D.; Food Chem. 2015, 168, 270.

28. Chhater, S.; Praveen, K.; Am. J. Biomed. Res. 2013, 1, 57.

29. Job, P.; Ann. Chim. 1928, 9, 113.

30. Dunning, T. H.; J. Chem. Phys. 1989, 90, 1007.

31. Stevens, W. J.; Basch, H.; Krauss, M.; J. Chem. Phys. 1984, 81, 6026. 
32. Tomasi, J.; Mennucci, B.; Cammi, R.; Chem. Rev. 2005, 105, 2999.

33. Frisch, M. J.; Trucks, G. W.; Schlegel, H. B.; Scuseria, G. E.; Robb, M. A.; Cheeseman, J. R.; Scalmani, G.; Barone, V.; Mennucci, B.; Petersson, G. A.; Nakatsuji, H.; Caricato, M.; Li, X.; Hratchian, H. P.; Izmaylov, A. F.; Bloino, J.; Zheng, G.; Sonnenberg, J. L.; Hada, M.; Ehara, M.; Toyota, K.; Fukuda, R.; Hasegawa, J.; Ishida, M.; Nakajima, T.; Honda, Y.; Kitao, O.; Nakai, H.; Vreven, T.; Montgomery Jr., J. A.; Peralta, J. E.; Ogliaro, F.; Bearpark, M.; Heyd, J. J.; Brothers, E.; Kudin, K. N.; Staroverov, V. N.; Kobayashi, R.; Normand, J.; Raghavachari, K.; Rendell, A.; Burant, J. C.; Iyengar, S. S.; Tomasi, J.; Cossi, M.; Rega, N.; Millam, N. J.; Klene, M.; Knox, J. E.; Cross, J. B.; Bakken, V.; Adamo, C.; Jaramillo, J.; Gomperts, R.; Stratmann, R. E.; Yazyev, O.; Austin, A. J.; Cammi, R.; Pomelli, C.; Ochterski, J. W.; Martin, R. L.; Morokuma, K.; Zakrzewski, V. G.; Voth, G.; Salvador, P.; Dannenberg, J. J.; Dapprich, S.; Daniels, A. D.; Farkas, O.; Foresman, J. B.; Ortiz, J. V.; Cioslowski, J.; Fox, D. J.; Gaussian 09, Revision D.1; Gaussian, Inc., Wallingford, CT, 2009.

34. Allouche, A.-R.; J. Comput. Chem. 2011, 32, 174.

35. Higuchi, T.; Connors, K. A.; Adv. Anal. Chem. Instrum. 1965 , $4,117$.

36. Locuson, C. W.; Wahlstrom, J. L.; Rock, D. A.; Rock, D. A.; Jones, J. P.; Drug Metab. Dispos. 2003, 31, 967.
37. Liu, M.; Guo, Q.; Shi, Y.; Cai, C.; Pei, W.; Yan, H.; Jia, H.; Han, J.; J. Mol. Struct. 2019, 1179, 336.

38. Jadhav, G. S.; Vavia, P. R.; Nandedkar, T. D.; AAPS PharmSciTech 2007, 8, E61.

39. Lucas-Abellán, C.; Fortea, M.; Gabaldón, J.; Núñez-Delicado, E. N.; Food Chem. 2008, 111, 262.

40. Usero, R.; Alvariza, C.; Gonzalez-Alvarez, M. J.; Mendicuti, F.; J. Fluoresc. 2008, 18, 1103.

41. Jullian, C.; Orosteguis, T.; Perez-Cruz, F.; Sanchez, P.; Mendizabal, F.; Olea-Azar, C.; Spectrochim. Acta, Part A 2008, $71,269$.

42. de Sousa, F.; Denadai, A.; Lula, I.; Lopes, J.; dos Santos, H.; de Almeida, W.; Sinisterra, R.; Int. J. Pharm. 2008, 353, 160.

43. Passos, J. J.; Sousa, F. B. D.; Lula, I. S.; Barreto, E. A.; Lopes, J. F.; Almeida, W. B. D.; Sinisterra, R. D.; Int. J. Pharm. 2013, $444,201$.

44. Tasi, G.; Mizukami, F.; Pálinkó, I.; Csontos, J.; Györffy, W.; Nair, P.; Maeda, K.; Toba, M.; Niwa, S.-i.; Kiyozumi, Y.; Kiricsi, I.; J. Phys. Chem. A 1998, 102, 7698.

Submitted: December 6, 2019 Published online: March 16, 2020 